\title{
Revealing Storage-area Relationship of Open Water in Ungauged Subalpine Wetland - Napahai in Northwest Yunnan, China
}

\author{
LI Jie ${ }^{1}$, HU Jin-ming ${ }^{1 *}$, DENG Wei², HUANG Sheng-li³, JIA Hai-feng ${ }^{1}$, ZHU Chun-ling ${ }^{1}$, \\ LUO Huai-xiu ${ }^{1}$ \\ 1 Asian International Rivers Centre, Yunnan University, Kunming 650091, China \\ 2 Institute of Mountain Hazards and Environment, Chinese Academy of Sciences, Chengdu 610o41, China \\ 3 ASRC Research and Technology Solutions, US Geological Survey (USGS) Earth Resources Observation and Science \\ (EROS), 47914 252nd Street, Sioux Falls, SD 57198, USA \\ *Corresponding author, e-mail: jhuynu@163.com; First author, e-mail:15368892723@126.com
}

(C) Science Press and Institute of Mountain Hazards and Environment, CAS and Springer-Verlag Berlin Heidelberg 2013

\begin{abstract}
Mountains and plateaus in Southwest China contain many subalpine and alpine wetlands, with significant hydroecological functions. But ungauged or poorly gauged conditions limit the study and understanding of hydrological regimes of these wetland types. This study selects an ungauged subalpine wetland - Napahai in Northwest Yunnan, China - as a case for developing a practical approach to revealing its storage-area relationship of open water. A Trimble R8 GNSS (Global Navigation Satellites Systems) RTK (Real-time Kinematic system) and sonar fathometer were used to survey fineresolution elevation data and generate a digital elevation model of the Napahai Wetland. Forty-four Landsat images from 1987 to 2011 were collected, and the Normalized Difference Water Index was used to classify open water features in the area. The area of open water in Napahai was calculated for each phase. With these data and a developed conceptual model, the storage of open water for each phase was estimated using ArcGIS tools. Both storage and area of open water showed significant intra-annual and inter-annual variations. In the rainy season, the monthly change of average storage of open water in Napahai showed about 1-2 months lag behind mean monthly rainfall. The storage-area relationship of open water was well fit by a power function equation $\left(R^{2} \approx 0.91, n=44\right)$. This study indicates that if detailed
\end{abstract}

Received: 14 November 2012

Accepted: 9 January 2013 elevations are available for similarly ungauged subalpine wetlands in Southwest China, researchers can use this practical approach to estimate multitemporal areas and storages and reveal the storagearea relationship of open water in the wetlands. The study provided valuable information of this case wetland for optimizing its hydro-ecological managements and a new method to wetland researchers and managers for the hydrological study of similarly ungauged wetland complex.

Keywords: Water storage; Ungauged wetland; Napahai Wetland; Normalized Difference Water Index

\section{Introduction}

Wetlands are characterized by temporal fluctuations of water levels, and hydrology controls or affects chemical and biological processes (Deng 2007; Hollis and Thompson 1998; Krasnostein and Oldham 2004). As hydrological response units in a catchment, wetlands have an important regulation capacity of hydrology (Mitsch and Gosselink 2007; Huang et al. 2011b). Describing wetland hydrology is very important for understanding how wetland systems function and change (Bradley 2002; Burt 
et al. 2002).

The mountains and plateaus in Southwest China contain many subalpine and alpine wetlands with a variety of ecological functions, e.g., conserving upstream soil and water, maintaining rich biodiversity, and regulating floodwater capacity (Bai 2008; Gujja et al. 2003). Because of human-induced disturbances and climate change, some subalpine or alpine wetlands have experienced substantial hydrological and ecological changes over the past several decades (Wang et al. 2001; Wang et al. 2008; Wang et al. 2011). For example, the area of alpine wetland on the Qinghai-Tibetan Plateau has decreased more than 10\% since the 1960s (Zhang et al. 2011). Most of these wetland types are traditionally ungauged or poorly gauged, which limit their hydrological study.

Wetlands have different and more complicated hydro-regime than rivers and lakes in runoff patterns (Krasnostein and Oldham 2004). Ordinary hydrological monitoring such as water level and flow velocity are widely used for long term hydrologic monitoring; however, these methods are labor-intensive for a wetland complex like Napahai where there are numerous geographically isolated depressions containing water when the water is very low. Scientists often chose area $(A)$ and storage $(V)$ of open water for their estimation and modeling (Frappart et al. 2010). $A$ can be used to depict the flooding situations and wetland dynamics, while $V$ can be used to explore wetland water balance. Remote sensing (RS) technologies are often used to estimate $A$, for example, the Normalized Difference Water Index (NDWI) was developed to classify and map regional open water using RS (remote sensing) images (Huang et al. 2011b; Ji et al. 2009; Mcfeeters 1996; Xu 2006). Zhang et al. (2006) used satellite altimetry data to derive the water level of Lake Dongting and calculated its water storage with other ground-measured data. Huang et al. (2011b) modeled the floodwater mitigation potential (maximum storage) of the Prairie Pothole Region (PPR) wetlands of North America, using Light Detection And Ranging (LIDAR) and other field-surveyed data.

For the topographic depression wetland with a horizontal water surface, its storage $(V)$ and area $(A)$ can be estimated from predetermined $A-h$ and $V-$ $h$ relations by measuring the depth $(h)$ of open water at the deepest point in the depression. In the study of 27 small natural depressions in PPR of North America, Hayashi and van der Kamp (2000) found $A-h$ and $V-h$ relations can be expressed as power functions and proposed a simplified $V-h$ and $A-h$ estimation method by using two morphological parameters of each depression. It provides a practical and time-saving approach to investigate the storage and area of open water for similar topographic depression wetlands (Minke 2009; Minke et al. 2010). Wiens (2001) and Gleason et al. (2007) also found strong statistical $V-A$ relationships for the PPR depression and proposed a power function to depict the $V-A$ relationship, which assists in the estimation of the storage of open water for similar topographic depressions. These two methods are based on the statistical $A-h, V-h$ or $V-A$ relations of individual topographic depressions. If examining a wetland with a vast number of depressions, the situation is more complicated due to the "fill and spill" mechanism (Huang et al. 2011b). In the PPR wetlands study, Huang et al. (2011b) established a model to calculate the floodwater storage (potential) at a landscape level.

In the hydrological study of wetlands, interannual and intra-annual dynamic of water storage capacity are often required for ecological service studies such as waterfowl and nutrition management. If the $V-A$ relationship is known, the water storage can be obtained by monitoring temporal change of $A$. The objective of this paper was to investigate the $V-A$ relationship for a selected Napahai Wetland, a representative subalpine wetland in Southwest China. To do this, we surveyed fine-resolution DEM of the wetland complex, then we used Landsat images to depict temporal open water area $(A)$, subsequently we estimated the water volume ( $V$ ) by combining DEM and water area, and finally we examined the $V-A$ relationships. We expect this study results can help local government and the managers of Napahai reserve to optimize the conservation of the wetland habitats and prevent the surrounding villages from the potential wetland floods.

\section{Study Area}

The Napahai Wetland $\left(99^{\circ} 37^{\prime}-99^{\circ} 43^{\prime} \mathrm{E}, 27^{\circ} 49^{\prime}\right.$ 
$\left.-27^{\circ} 55^{\prime} \mathrm{N}\right)$ is in the Hengduan Mountains of Southwest China (Figure 1). The area of the Napahai Wetland encompassed by the red line is about $31 \mathrm{~km}^{2}$. Its elevation ranges from 3261 to $3284 \mathrm{~m}$. Surface and underground runoff in the catchment converge on and form the wetland, and underground karst rivers to its north are major outlets. Wetland features in Napahai can be classified as open waters, streams and channels, wet meadows, marshes, and others. The Nahapai Wetland was designated as one of International Importance in February 2004 on the Ramsar list of Wetlands for the conservation of rare and endangered waterfowls (such as the Black-necked Crane and Black Stork) and their habitats (http://www.ramsar.org/doc/sitelist.doc).

A southwest monsoon climate, converging inflow, and underground outflow largely determine spatiotemporal variation of the hydrological regime in Napahai Wetland, which drives both seasonal and annual ecological dynamics of the wetland. Wetland degradation over the past several decades has been substantial (Hu et al. 2010, 2011, 2012; Li et al. 2010; Xiao et al. 2006; Zhang et al. 2007). Human-induced hydrologic change was one of the major culprits of this degradation. Furthermore, abundant precipitation in the catchment during the rainy season sometimes caused severe inundation. For example, open water areas on 25 August and 10 September 2002 (Table 1) covered approximately $85 \%$ and $91 \%$ of the wetland, respectively.

\section{Data Collection and Processing}

\subsection{Landsat image data}

Forty-four Landsat TM/ETM+ images from 1987 to 2011 were collected for classifying open water features and calculating their areas in the Napahai Wetland (Table 1). Due to frequent cloud covering from May to October, only a few images of good quality were available for this time period. Considering the significant fluctuation of area and storage of open water in the area, we sorted 3-5 images for each month in rainy season. Furthermore, to capture monthly dynamics of the open water, we also tried to sort images by month in a year; e.g., 10 images in 2002 (Table 1).

We first geo-referenced (WGS-84, Universal Transverse Mercator (UTM) Zone $47 \mathrm{~N}$ ) all Landsat images, then we conducted radiometric calibration as described by Chander et al. (2009). Using the NDWI proposed by Ji et al. (2009), we calculated forty-four phases of the Napahai Wetland's NDWI with the images. Because the NDWI is sensitive to open water, via threshold setting, we classified open water features and calculated their areas. We ignored rivers and canals, because widths of these features $(<10 \mathrm{~m})$ are less than the ground resolution of a Landsat image pixel $(30 \mathrm{~m})$. Each phase of NDWI-derived area of open water is listed in Table 1, followed by the corresponding Landsat image.

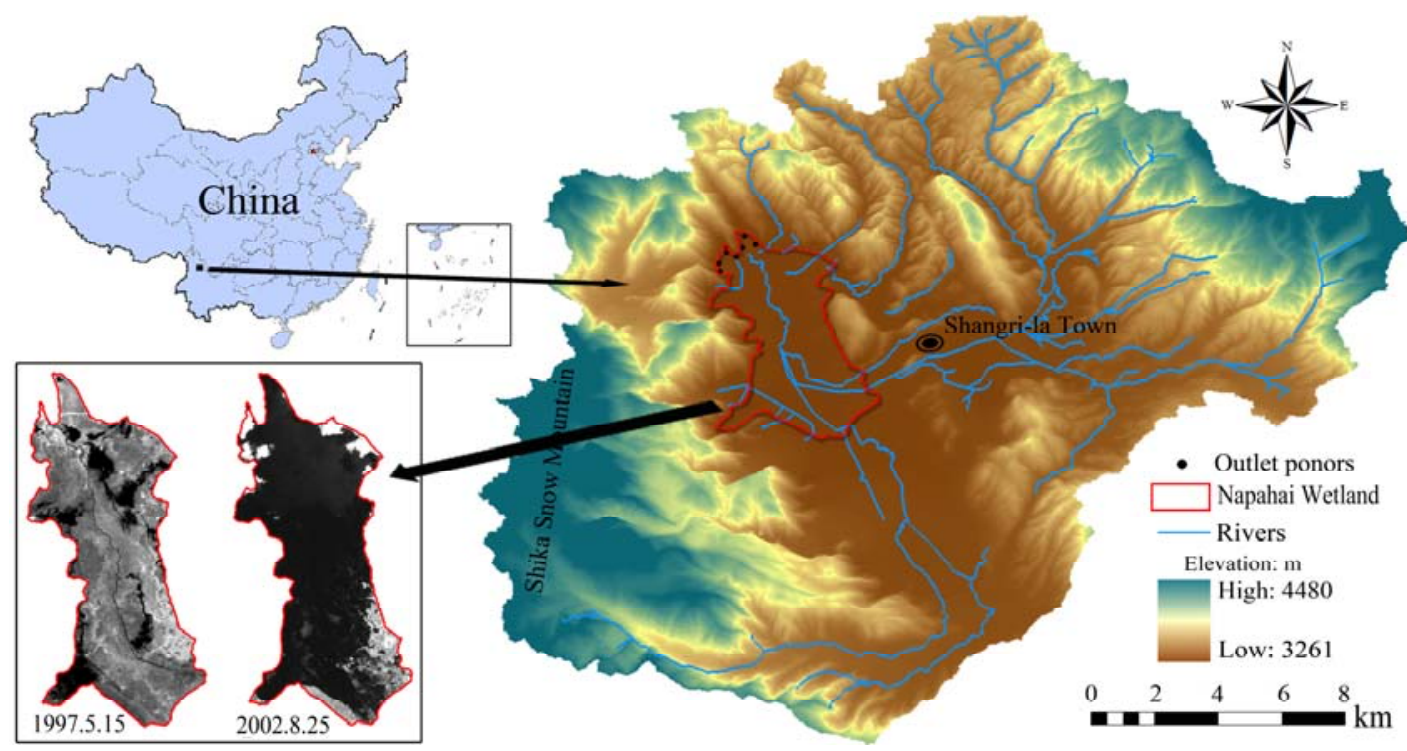

Figure 1 Location of Napahai Wetland and catchment, China. Lower left panel shows areas of open water (black) in the wetland, in mid-May 1997 (dry season) and late August 2002 (rainy season). 
Table 1 Landsat-derived area $\left(\mathrm{km}^{2}\right)$ and storage $\left(10^{4} \mathrm{~m}^{3}\right)$ of open waters in Napahai Wetland, China

\begin{tabular}{|c|c|c|c|c|c|c|c|c|c|}
\hline ID & Time phase & Sensor & Area & Storage & ID & Time phase & Sensor & Area & Storage \\
\hline 1 & $1987-02-13$ & $\mathrm{TM}$ & 3.061 & 164.85 & 23 & 2001-03-15 & ETM+ & 1.394 & 31.53 \\
\hline 2 & $1990-05-12$ & $\mathrm{TM}$ & 1.521 & 73.65 & 24 & 2001-04-16 & ETM+ & 2.407 & 103.55 \\
\hline 3 & $1990-06-13$ & $\mathrm{TM}$ & 3.190 & 157.04 & 25 & 2002-01-13 & ETM+ & 2.155 & 112.88 \\
\hline 4 & 1992-06-02 & $\mathrm{TM}$ & 2.324 & 74.91 & 26 & 2002-10-12 & ETM+ & 20.897 & 1972.87 \\
\hline 5 & 1992-08-05 & $\mathrm{TM}$ & 7.178 & 352.23 & 27 & $2002-10-28$ & ETM+ & 16.862 & 1124.48 \\
\hline 6 & $1994-11-15$ & TM & 1.224 & 17.01 & 28 & 2002-11-29 & ETM+ & 3.491 & 210.93 \\
\hline 7 & $1996-02-15$ & TM & 4.470 & 211.15 & 29 & $2002-12-31$ & ETM+ & 4.043 & 271.61 \\
\hline 8 & $1997-05-15$ & $\mathrm{TM}$ & 0.622 & 4.28 & 30 & 2002-03-02 & ETM+ & 2.238 & 63.5 \\
\hline 9 & 1997-09-20 & TM & 11.079 & 425.15 & 31 & 2002-05-05 & ETM+ & 1.961 & 113.4 \\
\hline 10 & 1998-01-10 & TM & 3.079 & 39.94 & 32 & 2002-07-16 & ETM+ & 7.788 & 444.79 \\
\hline 11 & 1998-09-07 & TM & 16.325 & 1052.96 & 33 & 2002-08-25 & ETM+ & 26.458 & 2655 \\
\hline 12 & 1999-11-21 & $\mathrm{TM}$ & 2.975 & 137.81 & 34 & 2002-09-10 & ETM+ & 28.481 & 4336.83 \\
\hline 13 & 1999-12-07 & $\mathrm{TM}$ & 2.482 & 72.34 & 35 & $2003-11-24$ & TM & 1.170 & 52.85 \\
\hline 14 & 1999-08-01 & ETM+ & 6.799 & 463.85 & 36 & 2003-06-01 & ETM+ & 1.230 & 58.15 \\
\hline 15 & 2000-10-06 & ETM+ & 9.681 & 342.11 & 37 & $2004-11-26$ & $\mathrm{TM}$ & 2.611 & 142.3 \\
\hline 16 & $2000-10-22$ & ETM+ & 4.739 & 368.42 & 38 & 2004-07-05 & $\mathrm{TM}$ & 3.283 & 70.94 \\
\hline 17 & $2000-11-07$ & ETM+ & 3.619 & 194.08 & 39 & $2005-11-13$ & TM & 2.533 & 113.31 \\
\hline 18 & $2000-12-25$ & ETM+ & 3.406 & 117.07 & 40 & $2005-09-10$ & TM & 10.905 & 440.9 \\
\hline 19 & $2000-04-13$ & ETM+ & $4 \cdot 314$ & 220.37 & 41 & 2006-07-27 & TM & 3.738 & 159.55 \\
\hline 20 & $2000-09-20$ & ETM+ & 17.150 & 943.63 & 42 & 2009-07-19 & TM & 4.807 & 287.79 \\
\hline 21 & $2001-11-10$ & ETM+ & 2.447 & 146.04 & 43 & 2010-08-07 & TM & 19.470 & 1691.95 \\
\hline 22 & $2001-12-12$ & ETM+ & 2.391 & 76.18 & 44 & $2011-08-10$ & TM & 7.141 & 491.72 \\
\hline
\end{tabular}

Data sources: Center for Earth Observation and Digital Earth of Chinese Academy of Sciences (CAS); USGS inventory of imagery (http://glovis.usgs.gov)

\subsection{Surveyed fine-resolution elevation data}

Currently DEM data generated from topographic map with scale 1: 50,000 cannot meet the modeling demands in this study for their rough characterization of the floodplain in the mountains. The Advanced Space-borne Thermal Emission and Reflection Global DEM (ASTER GDEM) data are also not feasible because the topography under the water is not revealed. We used a Trimble R8 GNSS RTK system to survey elevations of bare-earth regions and shallow open waters (accessible via walking). For deep open water inaccessible to walking, we first measured surface elevations at multiple marginal points of those waters. Then, we boated to measure water depth at multiple points within the waters with a sonar fathometer. Finally, we calculated the bathymetry of multiple bottom points within the deep open waters. Rivers and canals were ignored in the bathymetric survey, because they cannot be classified by the NDWI with Landsat images due to low image resolution (30 $\mathrm{m})$.
The field elevation survey was carried out in the dry season of 2011-2012, when a large percentage of the wetland had bare earth or was accessible to walking; the area covered by deep water in the wetland was small. We obtained elevations at 6,512 points (over 200 points per square kilometer), well distributed within the wetland. We generated the Napahai DEM using the surveyed elevation data and ArcGIS-Triangular Irregular Networks (TIN) model.

\section{Methodology}

\subsection{Conceptual model}

We first conceptualized the Napahai Wetland as a large topographic depression containing a series of smaller depressions of different morphologies (Figure 2). We named the small topographical depressions "ponds". We assumed that open water in each pond had a horizontal water surface. Altitude at any marginal point (e.g., 

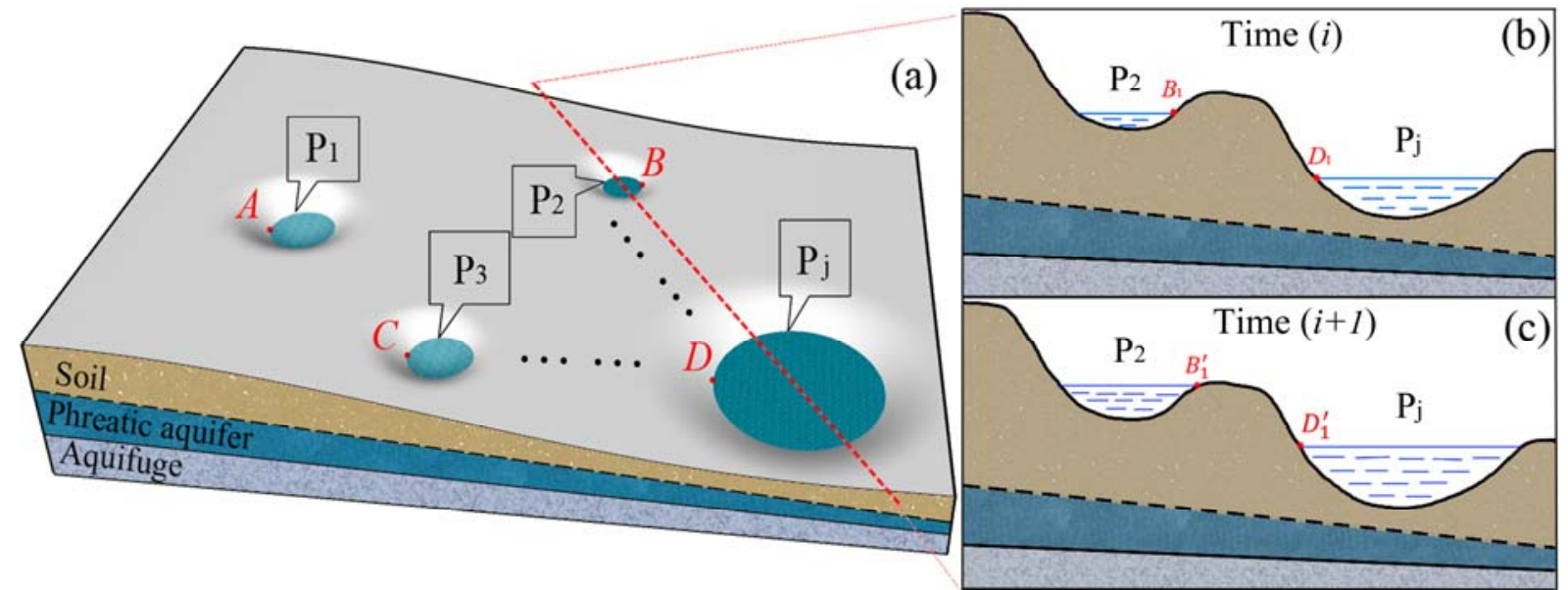

Figure 2 Conceptual model for calculating storage $(V)$ of open water in depressions of Napahai. a) conceptualized Napahai Wetland containing different sizes of depressions $\left(P_{j}\right)$. b) and c) hydrologic status at times $i$ and $(i+1)$ along transects $\mathrm{P}_{2}$ and $P_{j}$, respectively.

A, B, C in Figure 2a) of the open water patch can characterize altitude of the open water surface in the corresponding pond $\left(\mathrm{P}_{1}, \mathrm{P}_{2}, \mathrm{P}_{3}\right.$ in Figure 2a). If a fine-resolution DEM of a region is available, we could extract the altitude at any marginal point of the open water patch of each pond ( $P_{j}$ in Figure 2a), i.e., the altitude of the open water surface of the corresponding pond. With this altitude and the fine-resolution DEM of each pond, the depth $\left(h_{P_{j}}\right)$ of open water at the deepest point of each pond can be calculated. For open water of any pond at time $i$ (e.g., $P_{j}$ in Figure 2b), its dynamics of spatial distribution and area $\left(A_{P_{j}}^{i}\right)$ can be classified and calculated using the RS image and NDWI. At time $i$ (Figure 2b), the area $\left(A_{i}\right)$ of open water in the wetland is the sum of $A_{P_{j}}^{i}$.

As mentioned above, if we obtained the fineresolution DEM of the wetland, depth $\left(h_{P_{j}}^{i}\right)$ at the deepest point and the area $\left(A_{P_{j}}^{i}\right)$ of open water in each wetland pond $\left(P_{j}\right)$ at time $i$, the storage $\left(V_{P_{i}}^{i}\right)$ of open water in each pond in the wetland could be calculated (Hayashi and van der Kamp, 200o), and the total storage $\left(V_{i}\right)$ of open water - the sum of $V_{P_{i}}^{i}$ could also be calculated at the same time. Earlier datasets state that the fine-resolution Napahai DEM was generated through detailed field GNSS RTK surveys. Forty-four phases of open water features in the Napahai Wetland were classified using the NDWI. The only requirement was to acquire accurate altitudes of the open water surface of each pond.

\subsection{Extracting altitude of open water surface in ponds}

We assumed that a pond has horizontal water surface, which means that the water surface altitude at any point in the pond can represent the water surface altitude of the open water patch of the pond. That is to say, we can survey the water surface elevation at any point within the open water patch or along its edge. Usually, a point along the edge of the open water feature was preferred, because of its easy accessibility. As shown in Figure 3a, the altitude at any point from ' $\mathrm{E}$ ' to 'O' along the edge can be surveyed and assigned to the altitude of this open water surface.

We classified forty-four phases of open water features in the Napahai Wetland. Each phase was individually overlaid with the Napahai DEM in ArcGIS (Figure 3b). Steps for each phase: 1) We first generated all vertices (points) of each open water patch using the ArcGIS tool "Feature Vertices to Points"; 2) then, we gained altitude values of all vertices (points) from the DEM using the ArcGIS tool "Extract Value to Points."

According to assumption, the altitude at any vertex of a specified open water patch can be assigned as the water surface altitude of that feature. But the generated Napahai DEM via the GNSS survey and ground resolution of Landsat images can cause certain errors as assigning the altitude of any vertex to its corresponding open water patch. To mitigate this effect, we averaged 


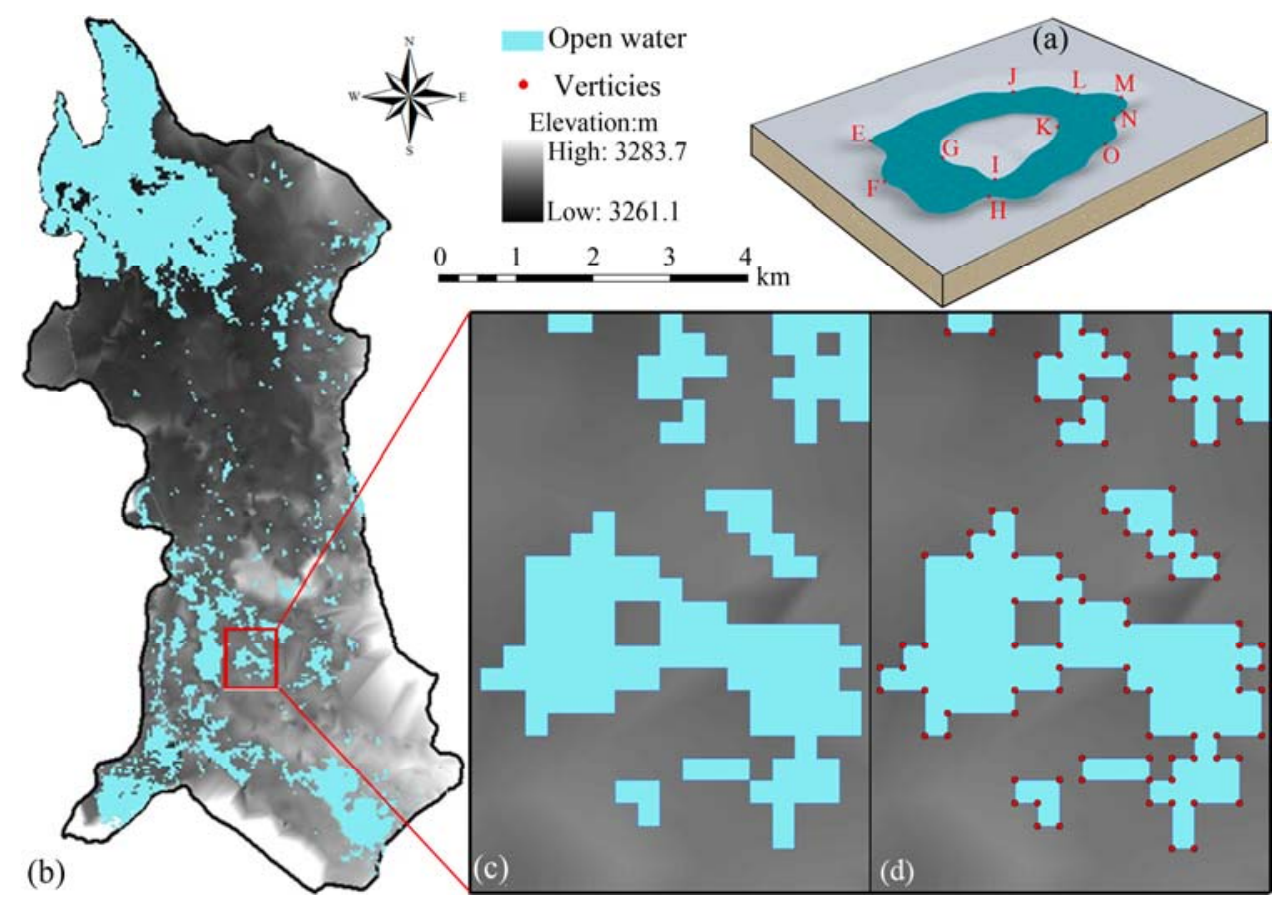

Figure 3 Extracted altitudes of open water surfaces. a) open water patch and marginal points along its outer and inner edges; b) One phase of open water features classified and digitized from Landsat image, using NDWI overlaid on Napahai DEM; c) section containing open water features cut from Figure $3 b$; d) the same as panel c, but showing vertices along edges of digitized open water features. Open water patch in panel a can be conceptualized as central largest digitized open water feature in panels $\mathrm{c}$ and $\mathrm{d}$.
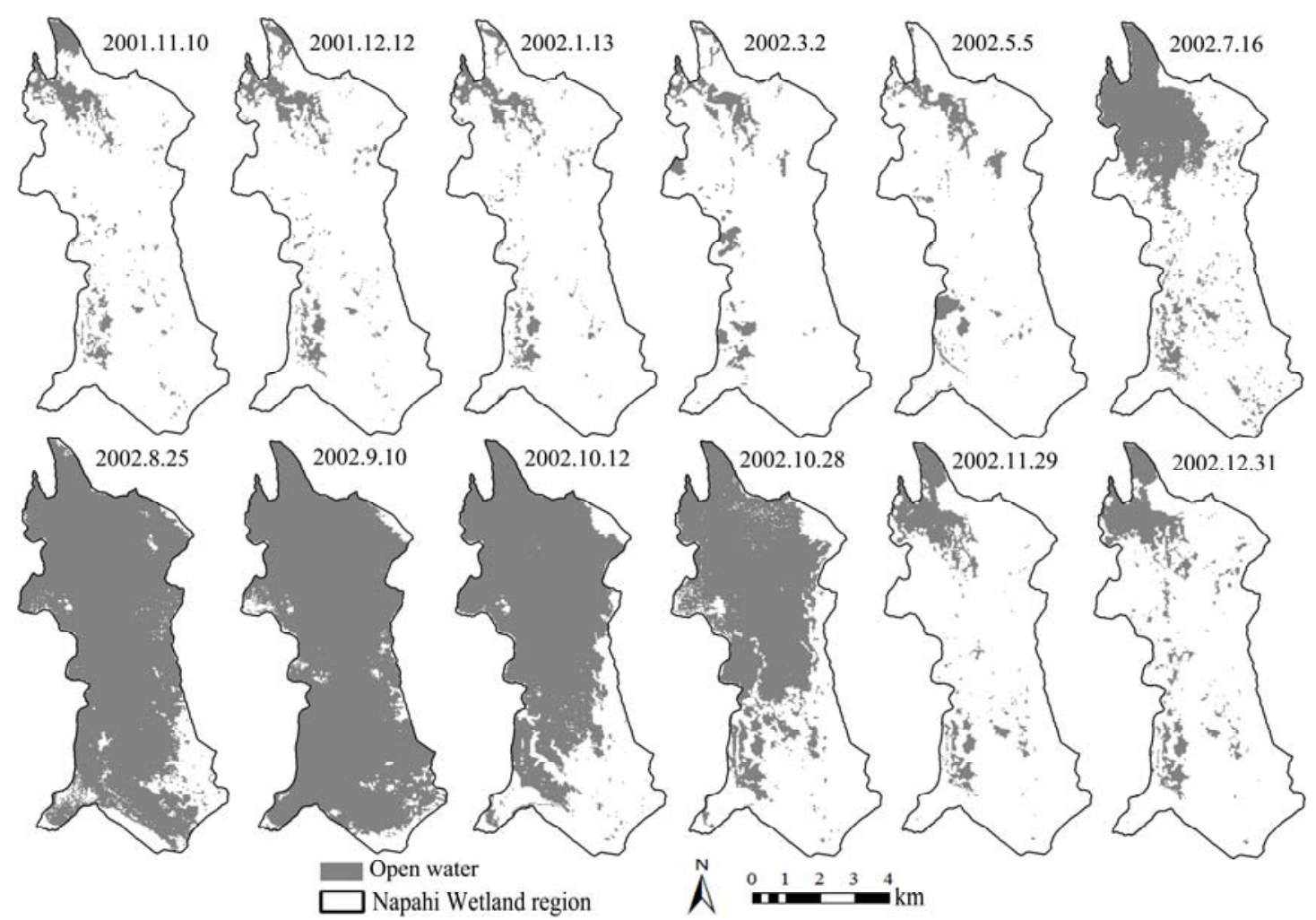

Figure 4 Change in areas of open water in Napahai, China from November 2001 to December 2002 
altitudes of these vertices (red points in Figure 3a) and assigned the averages to the water surface altitude of each specified open water patch. This method improved altitude estimation of the water surface of larger open water patches.

\subsection{Estimating water storage in Napahai}

According to the conceptual model in Section 3.1 and with the data of NDWI-derived area and extracted surface altitude of open water in a pond, along with the fine-resolution Napahai DEM, we estimated storage of open water in the pond using the ArcGIS tool "TIN polygon volume." By totaling storage of open water in each pond for one phase, we obtained storage of open waters in Napahai for that phase. We obtained forty-four phases of water storage in Napahai (Table 1).

\section{Results and Discussion}

\subsection{Fluctuation of hydrologic regime of the Napahai Wetland}

Estimated areas and storages of open water from forty-four Landsat images depict intra-annual and inter-annual fluctuations of hydrologic regimes of Napahai (Table 1; Figures 4 and 5). For the hydrologic year November 2001 to December 2002, Figure 4 shows that the area of open waters in Napahai had an obvious monthly fluctuation and significant variation between rainy and dry seasons. In the dry season, the area of open waters was small with slight fluctuation. In the rainy season, this area increased rapidly from mid-July through September; it declined gradually through midOctober and then sharply through November. In 2002, late August to mid-October was the major flooding period.

Open points in Figure 5 show large interannual variation in the area of open waters from August-October. Estimated storages of these waters in June and July both had less variation than in the following three months. Average storage in June nearly equaled that in May; in July, average storage slightly increased relative to June. For each month from November to the following May, estimated storages had low inter-annual variation. Comparing the solid and dashed lines in Figure 5, average monthly storages had fluctuations similar to that of monthly rainfall in the rainy season, but with a lag of 1-2 months. In the dry season, there were no obvious storage changes, owing to low rainfall with slight fluctuation.

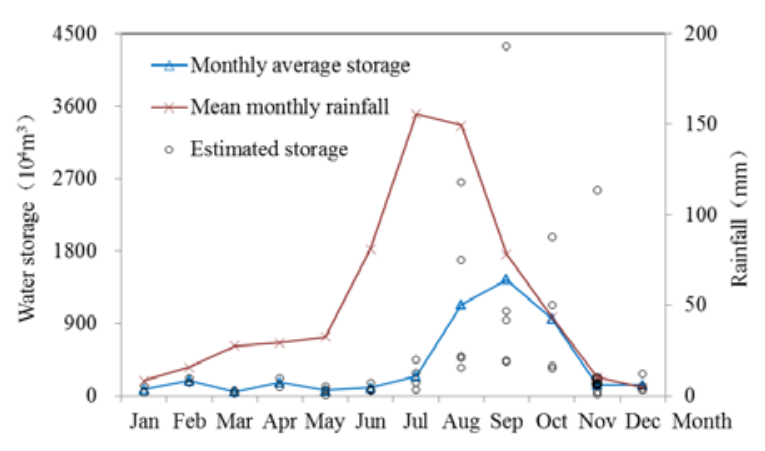

Figure 5 Variation of regional mean monthly rainfall and storage of open water in Napahai, China. Dashed line with open triangle label is mean monthly rainfall within the Napahai catchment. Open points are estimated storage of open water for each phase. Solid line with cross label is monthly average storage of open water from estimated storage.

NDWI-derived areas of open water using 23 images in the dry season (winter to spring) (Table 1) ranged from about $0.622 \mathrm{~km}^{2}(2.01 \%$ of wetland area) to $4.470 \mathrm{~km}^{2}(14.42 \%)$, which indicates that the open water area was small with slight fluctuation. During this dry season, the open waters and neighboring wetland patches (e.g., wet meadow, marsh, and others) deserve conservation. That is because these wetland features are habitats of rare winter waterfowl, such as the Black-necked Crane and Black Stork (Feng 2008; Han et al. 2009; He et al. 2011; Wang et al. 2009). This is the major reason that Napahai Wetland was listed as a Ramsar site. Open water features in the dry season can be easily classified using the NDWI method, which helps managers examine distribution patterns and dynamic changes of winter waterfowl habitats.

NDWI-derived areas of open water from 21 images in the rainy season (August-October) ranged from about $1.229 \mathrm{~km}^{2}(3.96 \%)$ to 28.481 $\mathrm{km}^{2}$ (91.87\%). Ten phases occupied over $30 \%$ of the wetland area. Eight of these ten phases were from late August to early October, which is also the major flooding period in Napahai. Flooding could 
occupy over $90 \%$ of the wetland area with extreme catchment rainfall, as in September 2002. Figure 5 shows that the increase in monthly average storage of open water in Napahai lagged monthly rainfall by 1-2 months in the rainy season. Extreme flooding in the wetland attracted greater attention by the local government. Hence, local rainfall observations from June through August is potentially useful information for forecasting later flooding scenarios, which would improve local hydrologic management and flood control for the wetland and human landscape.

\section{2 $V-A$ relationship of open waters in Napahai}

We fitted the $V-A$ relationship of open water in Napahai using a power function equation. Figure 6 is a scatter plot of $V-A$ from the fitting equation. It clearly shows that the $V-A$ relationship is well fit by the power function equation $\left(R^{2}=0.91, n=44\right)$. As Table 1 and Figure 6 show, forty-four phases of NDWI-derived areas of open water ranged from $0.622 \mathrm{~km}^{2}$ (2.01\%) to $28.481 \mathrm{~km}^{2}$ (91.87\%), which covered most scenarios of areal percentage of open water. Hence, the $V-A$ equation in Figure 6 can be used to estimate the storage of open water in Napahai under most scenarios, which is an easier way to estimate the storage of open water in Napahai Wetland.

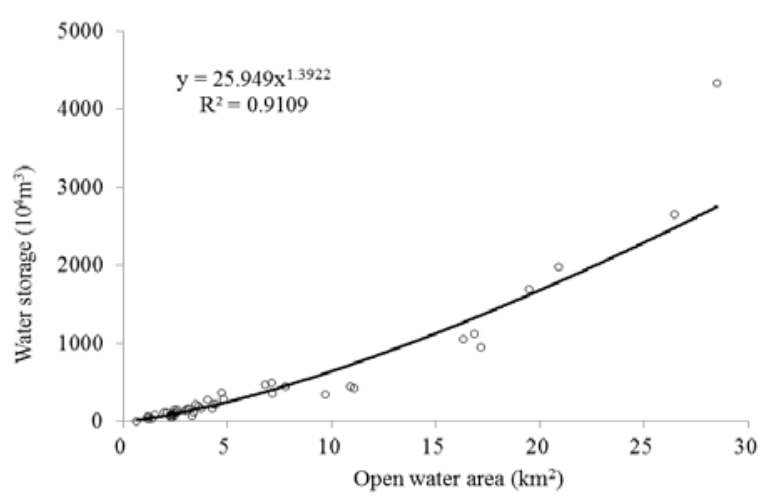

Figure $6 V-A$ relation of open water in Napahai Wetland, China fitted by power function equation

In hydrologic studies of PPR depression wetlands, Wiens (2001) developed an equation $\left(V=2.85 A^{1.22}\right)$ to depict surface $V-A$ relationships for wetlands smaller than 70 hectares. Gleason et al. (2007) derived three similar $V-A$ equations, for depressions in glaciated plains $\left(V=0.25 A^{1.4742}\right)$, the Prairie Coteau $\left(V=0.458 A^{1.5611}\right)$, and Missouri ( $V=0.398 A^{1.542}$ ). Comparing these fitting equations, we found that wetlands like Napahai or the PPR depressions had strong statistical relationships between open-water $V$ and $A$. Thus, the $V-A$ statistical relation of open waters can be fit by a power function equation. Given that this is a first trial, additional studies are necessary to determine whether the statistical $V-A$ relationship is applicable to subalpine or alpine wetlands similar to Napahai.

\subsection{Practicality and limitation of the approach}

The Napahai Wetland is a representative type of subalpine wetland in Southwest China, in terms of major hydrological controlling factors - a monsoon and plateau climate, and converging inflow resulting from catchment morphology. It is difficult to perform detailed hydrological surveys or monitoring for wetlands similar to the Napahai Wetland. For example, in low water level periods, depressions with open water are scattered across the wetland. In such periods, it is impractical or unnecessary to monitor each depression. But if we hope to explore spatiotemporal dynamics of wetland hydrologic regimes as a whole, we must acquire information on most of the depressions. Hence, the method proposed here is practical for revealing hydrologic regimes of this type of ungauged wetland. This is because multi-temporal medium- or high-resolution RS images (SPOT, Landsat TM/ETM+, ENVISAT ASAR, ALOS PALSAR, and others) are economically available and widely used to classify open water features. Fine-resolution elevations are also technically available.

Most determining and required data of this approach are fine-resolution elevations. Here, we used the GNSS RTK system to survey detailed elevation. If a wetland is easily accessible to walking during a certain period of the year and its area is not too large, detailed field surveys with the GNSS RTK system are practical and economical. However, they are time consuming and impractical for very large wetlands. LIDAR provides the possibility for acquiring fine-resolution elevation data over a large region. LIDAR has already been used successfully to obtain high-resolution wetland 
DEMs (Huang et al. 2011b; Lang and McCarty 2009; Minke 2009; Schumann et al. 2008), although it is still expensive. For subalpine or alpine wetlands similar to Napahai, LIDAR is suitable for obtaining elevation in the dry season, when large areas of the wetland have bare earth or very shallow open waters.

There are two error sources within RS image data. One is from the complex pixel effect. As Ji et al. (2009) pointed out, the effect of complex pixels, including water, soil and vegetation, can cause errors of interpretation, especially for the boundary of open water features. However, we expect that rapid development of RS detection technology will gradually decrease the complex pixel effect. Another source is pixel ground resolution of the RS images used. In this study, narrow-line wetland features (rivers and canals) of width less than $10 \mathrm{~m}$ could not be classified from Landsat images. Available high ground-resolution RS images can be used to mitigate the influences of these two error sources to a certain degree. Nevertheless, these error sources do not produce unacceptable deviation in the exploration of overall hydrology in large wetland regions.

The availability of satellite-based, visible RS images in the rainy season should also be considered. Here, only 21 Landsat images with slight cloud coverage were available in this season, from 1987 through 2011. Inevitably, some open water scenarios in the Napahai Wetland were not evidenced through the imagery available for this time period. Radar can penetrate cloud and detect open waters (Huang et al. 2011a; Wdowinski et al. 2008). Medium- or high-resolution synthetic aperture radar data, e.g., ENVISAT ASAR, ALOS PALSAR, provide optional RS images for solving the data limitation in the rainy season.

\section{Conclusions}

Through multi-temporal Landsat images and a detailed elevation survey in Napahai Wetland, we developed a practical approach for estimating multi-temporal areas and storages of open water in the Napahai Wetland at a landscape level under ungauged conditions. Forty-four phases of estimated $A$ and $V$ of open water clearly showed intra-annual and inter-annual hydrologic variations in the wetland. It showed extreme flooding could occupy over 90\% of wetland area. The major flooding period in Napahai was from late August to early October. Changes of open water storage (and area) in rainy season lagged monthly rainfall by $1-2$ months, which indicates that observed rainfall from June-August is useful for forecasting later flooding scenarios. The $V-A$ relationship of open water was fit by a power function equation, with a significant result $\left(\mathrm{R}^{2} \approx 0.91\right)$. The relationship can thus be used to estimate storage of open water in Napahai.

This is the first trial to explore hydrological regimes of an ungauged subalpine wetland in Southwest China. Remaining issues require attention to improve the approach in future studies. As noted above, one way to do this is via acquisition of detailed wetland elevation data. The GNSS RTK, airborne LIDAR, and other newly developed detecting technologies can be jointly used to improve resolution and accuracy of wetland elevations. Another way is to overcome the limitation of RS images. High-resolution RS images can mitigate the effects of the two major errors, and radar images can somewhat overcome the reduced availability of visible RS images caused by cloud cover. Therefore, under ungauged or poorly gauged conditions, our approach to estimate multi-temporal $\mathrm{V}$ and $\mathrm{A}$ and reveal $\mathrm{V}-\mathrm{A}$ relationships of open water in wetlands like Napahai at landscape level is practical and promising. The approach will improve hydrological and ecological studies of these types of wetlands, which are widely distributed in the mountains and plateaus of Southwest China.

The results of this case study can first provide valuable information to local Shangri-la government for optimizing the hydro-ecological management of the Wetland, e.g. quantifying the hydrological regimes in rainy and dry seasons to conserve its restoration, taking earlier measures to prevent the surrounding villages from extreme inundation through forecasting the potential flood scenarios with the rainfall information monitored. The integrated conceptual model established in this study also provides a new method to wetland researchers and managers for the hydrological studies of similarly ungauged wetland complex. 


\section{Acknowledgments}

This work was supported by the National Special Basic Research Fund (Grant No. 2008FY110300), National Science and Technology Support Program (Grant No. 2011BACo9Bo7), National Natural Science Foundation of China (Grant No. 40961003) and Scientific Research Fund Project of Yunnan Education Department

\section{Reference}

Bai JH (2008) Alpine wetlands in China. Chinese Forestry Press. p33. (In Chinese)

Bai JH, Ouyang H, Xu HF, et al. (2004) Advances in studies of wetlands in Qinghai-Tibet Plateau. Progress in Geography 23 (4): 1-9. (In Chinese)

Bradley C (2002) Simulation of the annual water table dynamics of a floodplain wetland, Narborough Bog, UK. Journal of Hydrology 261: 150-172. DOI: 10.1016/Soo22-1694(02) 00012-4

Burt TP, Pinay G, Matheson FE, et al. (2002) Water table fluctuations in the riparian zone: comparative results from a pan-European experiment. Journal of hydrology 265: 129-148. DOI: 10.1016/Soo22-1694(02)00102-6

Chander G, Markham B, Helder D (2009) Summary of current radiometric calibration coefficients for Landsat MSS, TM, ETM+, and EO-1 ALI sensors. Remote Sensing of Environment 113 (5): 893-903. DOI: 10.1016/j.rse.2009.01. 007

Cui BS, Yang ZF (2006) Wetlands. Beijing Normal University Press. pp1-34. (In Chinese)

Deng W (2007) Hydrological space effects of wetlands. Advances in Earth Science 22(7): 725-729. (In Chinese)

Frappart F, Papa F, Guntner A, et al. (2010) Interannual variations of the terrestrial water storage in the Lower Ob' basin from a multi satellite approach. Hydrology and Earth System Sciences 14: 2443-2453. DOI: 10.5194/hess-14-24432010

Feng L (2008) Wintering Ecology of Ciconia nigra at Napahai. Thesis of Master, Southwest Forestry University, Kunming, China. (In Chinese)

Gleason RA, Tangen BA, Laubhan MK, et al. (2007) Estimating Water Storage Capacity of Existing and Potentially Restorable Wetland Depressions in a Subbasin of the Red River of the North. US Geological Survey Open-File Report 2007-1159: 14-21

Gujja B, Chatterjee A, Gautam P, Chandan P (2003) Wetlands and Lakes at the Top of the World. Mountain Research and Development 23 (3): 219-221.

Han B, Feng L, Han LX, et al. (2009) Relationship between population fluctuation of wintering waterfowls and water area change in Napahai nature reserve. Journal of Southwest Forestry University 29(2): 44-46. (In Chinese)

Hayashi M, van der Kamp G (2000) Simple equations to represent the volume - area - depth relations of shallow wetlands in small topographic depressions. Journal of Hydrology 237: 74-85. DOI: 10.1016/Soo22-1694(00)00300o

He P, Kong DJ, Liu Q, et al. (2011) Roosting-site characteristics of wintering black-necked cranes (Grus nigricollis) at Napahai,
(Grant No. 2011Jo18). The authors give special thanks to local managers of the Napahai Wetland for helping with the field survey and anonymous reviewers for their constructive comments and suggestions. Any use of trade, product, or firm names is for descriptive purposes only and does not imply endorsement by any government.
Yunnan. Zoological Research 32(2): 150-156. (In Chinese)

Hollis G, Thompson JR (1998) Hydrological data for wetland management. Journal of the Chartered Institution of Water and Environmental Management 12(1): 9-17.

Hu JM, Li J, Yuan H, Dong YX (2010) Seasonal landscape pattern change and its driving forces of the Napahai Wetland. Geographical Research 29 (5): 899-908. (In Chinese)

Hu JM, Yuan H, Li J, et al. (2011) Variation of rapid available nitrogen components and its implication in Napahai lakemarsh region, northwest Yunnan mountain. Journal of Mountain Science 29 (3): 269-279. (In Chinese)

Hu JM, Dong YX, Yuan H, et al. (2012) Variation of soil organic C components under different degradation condition in Napahai Wetland reserve. Geographical Research 31(1): 53-62. (In Chinese)

Huang SL, Dahalb D, Young C, et al. (2011a) Integration of Palmer Drought Severity Index and remote sensing data to simulate wetland water surface from 1910 to 2009 in Cottonwood Lake area, North Dakota. Remote Sensing of Environment 115(12): 3377-3389. DOI: 10.1016/j.rse.2011. 08.002

Huang SL, Young C, Feng M, et al. (2011b) Demonstration of a conceptual model for using LiDAR to improve the estimation of floodwater mitigation potential of Prairie Pothole Region wetlands. Journal of Hydrology 405: 417-426. DOI: 10.1016/ j.jhydrol.2011.05.040

Ji L, Zhang L, Wylie B (2009) Analysis of Dynamic Thresholds for the Normalized Difference Water Index. Photogrammetric Engineering \& Remote Sensing 75 (11): 1307-1317.

Krasnostein AL, Oldham CE (2004) Predicting wetland water storage. Water Resources Research 40, W10203.

Lang M, McCarty G (2009) LiDAR intensity for improved detection of inundation below the forest canopy. Wetlands 29(4): 1166-1178. DOI: 10.1672/08-197.1

Li J, Hu JM, Dong YX, Yuan H (2010) Study on the landscape change from 1994 to 2006 of Napahai catchment and the wetlands, northwest Yunnan mountainous region. Journal of Mountain Science 28(2): 247-256. (In Chinese)

Mcfeeters SK (1996) The use of the Normalized Difference Water Index (NDWI) in the delineation of open water features. International Journal of Remote Sensing 17: 1425-1432. DOI: 10.1080/01431169608948714

Minke A (2009) Estimating Water Storage of Prairie Pothole Wetlands. Thesis of Master, University of Saskatchewan, Canada.

Minke A, Westbrook C, van der Kamp G (2010) Simplified Volume-Area-Depth Method for Estimating Water Storage of Prairie Potholes. Wetlands 30: 541-551. DOI: 10.1007/s13157010-0044-8 
Mitsch WJ, Gosselink JG (2007) Wetlands (4th Edition). New York: Wiley.

Ozesmi S, Bauer M (2002) Satellite remote sensing of wetlands. Wetlands Ecology and Management 10: 381-402. DOI: 10.1023/A:1020908432489

Schumann G, Matgen P, Cutler M, Shen YP (2008) Comparison of remotely sensed water stages from LiDAR, topographic contours and SRTM. ISPRS Journal of Photogrammetry and Remote Sensing 63: 283-296. DOI: 10.1016/j.isprsjprs.2007. 09.004

Wang GX, Li Q, Cheng GD (2001) Climate change and its impact on the eco-environment in the source regions of the Yangtze and Yellow Rivers in recent 40 years. Journal of Glaciology and Geocryology 23 (4): 346-352. (In Chinese)

Wang GX, Bai W, Li N, Hu HC (2011) Climate changes and its impact on tundra ecosystem in Qinghai-Tibet Plateau, China. Climatic Change 106: 463-482.

Wang H, Zhou XL, Wan CG, et al. (2008) Eco-environmental degradation in the northeastern margin of the QinghaiTibetan Plateau and comprehensive ecological protection planning. Environmental Geology 55: 1135-1147. DOI: 10.1007/s00254-007-1061-7

Wang K, Yang XJ, Zhao JL, et al. (2009) Relations of daily activity patterns to age and flock of wintering Black-necked Crane (Grus nigricollis) at Napa Lake, Shangri-La in Yunnan. Zoological Research 30(1): 74-82. (In Chinese)
Wdowinski S, Kim S, Amelung F, et al. (2008) Space-based detection of wetlands' surface water level changes from Lband SAR interferometry. Remote Sensing of Environment 112 (3): 681-696. DOI: 10.1016/j.rse.2007.06.008

Wiens L (2001) A surface area-volume relationship for prairie wetlands in the Upper Assiniboine river basin, Saskatchewan. Canadian Water Resources Journal 26(4): 503-513.

Xiao DR, Tian K, Zhang LQ (2008) Relationship between plant diversity and soil fertility in Napahai wetland in northwestern Yunnan Plateau. Acta Ecologica Sinica 28 (7): 3116-3124. (In Chinese)

Xu HQ (2006) Modification of normalised difference water index (NDWI) to enhance open water features in remotely sensed imagery. International Journal of Remote Sensing 27 (14): 3025-3033. DOI: 10.1080/01431160600589179

Zhang JQ, Xu KQ, Yang YH, et al. (2006) Measuring water Storage fluctuations in lake Dongting, China, by TOPEX/ POSEIDON satellite altimetry. Environmental Monitoring and Assessment 115: 23-37. DOI: 10.1007/s10661-006-5233-9

Zhang Y, Wang GX, Wang Y (2011) Changes in alpine wetland ecosystems of the Qinghai-Tibetan plateau from 1967 to 2004. Environmental Monitoring and Assessment 180: 189199. DOI: 10.1007/s10661-010-1781-0

Zhang K, Tian K, Mo JF, et al. (2007) Impact of hydrological periods on organic matter in Napahai Wetlands. Journal of Lake Science 19(6): 705-709. (In Chinese) 